\title{
Light Emitting Diodes
}

Light emitting diodes in use today are cheap, efficient and bright sources of light and are used in displays, communication and, increasingly, mass market consumer products such as automobile tail lights.

The development of LEDs, however, was far from straightforward. Indeed, today's accomplishments could be considered as fortuitous lights at the end of a very long, dark and tortuous tunnel.

Electroluminescence - the production of light due to the passage of electrical current through a material and the basis for the light emitting diodes - was first seen 80 years ago by radio researcher H.J. Round. He noticed that a current through a silicon carbide "cat's whisker" crystal at times produced a yellowish light.

While the phenomenon was not central to his work, Round was intrigued enough to write a "Note on Carborundum" to the journal Electrical World:

"During an investigation of the unsymmetrical passage of current through a contact of carborundum and other substances a curious phenomenon was noted. On applying a potential of 10 volts between two points on a crystal of carborundum, the crystal gave out a yellowish light."

Round noted that only a few whiskers did this at such low voltages, but many exhibited the behavior when the voltage was raised over 110 volts.

"The writer would be glad of references to any published account of an investigation of this or any allied phenomena."

Neither Round - nor anyone else apparently - pursued this effect further for at least 15 years. Indeed, Round's observations were forgotten until 1968 when this note was republished in IEEE Spectrum by Henry F. Ivey. Round's lack of followup can be explained by his and colleagues' preoccupation with developing radio receivers.

The next chapter in LED history is also not well known. It deals with the accomplishments of Oleg V. Losev, a brilliant Russian experimentalist who led an inspired but tragic life.

Losev packed many modern electronic discoveries into his 20 years of research. The story of Losev's role in LED development is included in a detailed history of the development of the device written by Egon E. Loebner in the July 1976 (Bicentennial) issue of IEEE Transactions on Electron Devices.

At the age of 19, Losev rediscovered in 1922 what Round had noticed - electroluminescence in silicon carbide. He later discovered zinc oxide radio frequency diode oscillators and amplifying detectors, and developed battery-powered "crystadyne" solid-state radio receivers that foreshadowed modern transistor radios.

Though his radio receivers were advanced for their day, tubes became the dominant amplification device technology. That turn of events, as well as trouble with an American vendor of the zinc oxide crystals he used, led Losev to change the thrust of his research. In 1927, Losev concentrated his efforts on the study of light emitting and light sensing diodes - a decision that would continue to keep him decades ahead of his contemporaries.

Losev correctly deduced that LED emission represents an inverse case of Einstein's photoelectric effect and, in 1930, described and characterized - without knowing it - what we now call a p-n junction. That his model for the junction's behavior differed from present day models by only one, admittedly crucial, feature (p-type hole current) is "an astounding accomplishment... considering ... the isolation of Soviet scientists and the difficulties Losev experienced due to a laboratory merger," Loebner wrote.

Unfortunately, lack of recognition or being ahead of his time was not the most serious tragedy to befall Losev.

Loev's commitment to his work was so strong he ignored the Academician Abram F. Ioffe's advice to evacuate the laboratory in advance of the German invasion of Russia early in World War II. He was caught in the blockade of Leningrad and died of hunger in January 1942.

"In some cases his experimental work was 40 years ahead of his time," wrote
Loebner, a Hewlett-Packard Laboratories researcher who gained access to many of Losev's papers when he served as a technical advisor in the U.S. Embassy in Moscow. "His research was so exact and his publications so clear that one has little difficulty determining today what he actally did in his laboratory then. His intuitive choice and design of experiments was simply astonishing."

"The careful, wise and diligent work of the young solid state device physicist shows not only unusual perseverence, but also signs of remarkable intuition for physical concept guided experimentation," Loebner added.

It was more than 10 years after Losev's death before LED research took another step forward.

Parallel semiconducter materials research (dating back to 1910) resulted in the first modern LEDs being produced nearly simultaneously in 1955 by groups led by Braunstein at RCA and Wolff at the Signal Corps Engineering Laboratories. They used III-V single crystals and germaniumsilicon alloys.

A great leap toward commercial use of LEDs occurred 25 years ago when four research groups announced in separate papers that they had obtained laser light from gallium arsenide crystals. These included groups from Lincoln Laboratory, headed by T.M. Quist; IBM, headed by M.I. Nathan; General Electric, headed by R.N. Hall; and the Soviet Union, led by D.N. Nasledov.

Widespread commercial success began after the first GaAsP LED displays were produced in 1968 by Hewlett-Packard and Monsanto.

In hindsight, Loebner says that if it had taken any longer to develop LEDs, they might not have been produced today at all. If LEDs were developed after liquid crystal displays were known, Loebner thinks industry would have not pursured LEDs nearly so vigorously.

M. ROSS

\section{Is there a topic you would like to read about in Historical Notes?}

\author{
Send suggestions and comments to: \\ Editor. MRS BULLETIN \\ Materials Research Society \\ 9800 McKnight Road. Suite 327 \\ Pittsburgh. PA 15237 \\ Telephone (412) 367-3036
}




\section{MATERIALS RESEARCH SOCIETY \\ 1987 Spring Short Course Program}

The Materials Research Society has slated a short course program on materials science topics to be run in conjunction with the Society's 1987 Spring Meeting to be held April 21-25, 1987 at the Anaheim Marriott Hotel/Anaheim, California. The program consists of twenty-one courses, which are either one, two, or three days in length.

Liquid Phase Epitaxy Techniques: $\$ 295$

Instructor: L.R. Dawson. April 21

Metalorganic Chemical Vapor Deposition: $\$ 295$ Instructor: P.D. Dapkus. April 22

Molecular Beam Epitay: $\$ 460$

Instructor: G.W. Wicks. April 23-24

Film Formation, Adhesion, and Surface

Preparation: $\$ 295$

Instructor: D.M. Mattox. April 24

Properties of Films and Coatings: $\$ 295$

Instructor: D.M. Mattox. April 25

Metallization for VLSI Technology: $\$ 460$

Instructors: S. Mahajan and K.S. Sree Harsha. April 21-22

IC Failure Analysis: $\$ 460$

Instructor: G. Riga. April 23-24

Vacuum Technology for Materials

Processing: $\$ 460$

Instructor: D.M. Mattox. April 21-22

Plasma Etching for Microelectronic

Fabrication: $\mathbf{\$ 2 9 5}$

Instructor: G.K. Herb. April 22

Hazardous Aspects of Semiconductor Device Processing: \$295

Instructor: G.K. Herb. April 21

Plasma Enhanced CVD of Thin Films for Microelectronics: $\mathbf{\$ 2 9 5}$

Instructor: R. Reif. April 24
Introduction to Transmission and Analytical

Electron Microscopy: $\$ 460$

Instructors: A.D. Romig, Jr. and D.B. Williams.

April 21-22

Deep Level Transient Spectroscopy: $\$ 295$

Instructor: C.E. Barnes. April 23

Surface and Thin Film Analysis: $\mathbf{\$ 4 8 0}$

Instructors: L.C. Feldman and J.W. Mayer. April 24-25

Amorphous Semiconductor Materials and

Devices: $\$ 295$

Instructor: D. Adler. April 25

Ion Beam Processes for Materials Modification: $\$ 295$

Instructor: J.K. Hirvonen. April 24

Rapid Thermal Processing: $\$ 295$

Instructors: T.E. Seidel and S.C. Shatas. April 24

Solid Lubricants and Tribological Properties of

Solids in Contact: $\mathbf{\$ 2 9 5}$

Instructor: D.H. Buckley. April 24

Introduction to Ceramic and Metal Matrix Composites: $\mathbf{\$ 4 6 0}$

Instructors: J.J. Mecholsky and M.F. Amateau. April 21-22

Sol-Gel Processing of Glass: $\$ \mathbf{4 6 0}$

Instructors: C.J. Brinker and G.W. Scherer.

April 21-22

Experimental Strategies for Optimizing Process Variables: $\$ \mathbf{6 2 5}$

Instructor: D.H. Doehlert. April 21-23

Note: Registrations received after April 1 and at the Spring Meeting are $\$ 25$ higher for each course.

Special discounts on tuition are offered to registrants attending certain groups of courses. For further details on courses, discount fees and instructors contact the Materials Research Society, 9800 McKnight Road, Suite 327, Pittsburgh, PA 15237. Telephone (412) 367-3003.

\section{ON-SITE COURSES}

On-Site courses can be tailored to the needs of the requesting organization and are offered on an instructor available basis. For details of On-Site courses contact: Vivienne Harwood Mattox

MRS Short Course Manager

Telephone (505) 294-9532. 